\title{
PENGARUH PERCEIVED USEFULNESS DAN PERCEIVED EASE OF USE TERHADAP KEINGINAN WAJIB PAJAK ORANG PRIBADI UNTUK MENGGUNAKAN E-BILLING PAJAK VERSI 2
}

\author{
Fransiskus Peter Livianto \\ Universitas Katolik Soegijapranata \\ peterlivianto@gmail.com
}

\begin{abstract}
The release of tax e-billing version 2 by the Directorate General of Taxes certainly got the pros and cons of the users. Any change of a certain system is not necessarily accepted by its users. In this case the conventional tax payment system is a paper-based Tax Payment Slip into a more modern Electronic Tax Payment Slip. Various factors can affect a person in the use of a technology, therefore this research would like to examine the factors that might affect the desire of individual taxpayers in the Cirebon City to use the tax e-billing version 2.

This study uses the theory of Davis F.D is the Technology Acceptance Model (TAM) this theory is very popular in research about the user perception of technology acceptance. In this study used two independent variables, first is perceived usefulness and the second is perceived ease of use and the dependent variable is behavioral intention to use.The study was conducted by spreading 500 questionnaires to Taxpayer in Cirebon City, and obtained valid questionnaires as many as 435 pieces. The questionnaire obtained will then be tested by means of regression test. In this study perceived usefulness and perceived ease of use significantly affect the desire of individual taxpayers to use the tax e-billing version 2.
\end{abstract}

Keywords :TAM, tax e-billing version 2, information system

\begin{abstract}
Abstrak
Berbagai faktor dapat mempengaruhi seseorang dalam penggunaan sebuah teknologi, maka dari itu penelitian ini ingin menguji faktor-faktor yang mungkin saja mempengaruhi keinginan Wajib Pajak Orang Pribadi di lingkup Kota Cirebon untuk menggunakan ebilling pajak versi 2 .

Penelitian ini menggunakan teori dari Davis F.D yaitu Technology Acceptance Model (TAM) yang sangat populer dalam penelitian tentang persepsi pengguna terhadap penerimaan teknologi. Dalam penelitian ini digunakan 2 variabel independen, yaitu perceived usefulness (persepsi kebermanfaatan) dan perceived ease of use (persepsi kemudahan dalam penggunaan) serta variabel dependennya behavioral intention to use (keinginan untuk menggunakan).Penelitian dilakukan dengan menyebar 500 buah kuesioner kepada Wajib Pajak Orang Pribadi yang terdaftar di Kota Cirebon, dan didapatkan kuesioner yang sah sebanyak 435 buah. Kuesioner yang diperoleh selanjutnya akan diuji dengan alat uji regresi. Dalam penelitian ini perceived usefulness dan perceived ease of use secara signifikan mempengaruhi keinginan Wajib Pajak Orang Pribadi untuk menggunakan e-billing pajak versi 2 .
\end{abstract}

Kata kunci : TAM, e-billing pajak versi 2, sistem informasi 


\section{PENDAHULUAN}

Pajak merupakan salah satu sumber pendanaan bagi sarana dan prasarana negara. Dengan adanya pajak, perekonomian dapat stabil dan terciptanya segala fasilitas publik yang memadai mulai dari sarana umum, pembangunan jembatan, pembangunan jalan, tercitanya transportasi publik dll.

Di era seperti sekarang ini, perkembangan teknologi semakin pesat dan semakin baik dari sebelumnya. Berbagai strategi pemerintah dalam memperbaiki sistem pemerintahan dengan teknologi semakin dikedepankan demi birokrasi yang lebih baik dan tertata. Beberapa bidang pemerintahan di Indonesia telah menggunakan teknologi dalam pelaksanaannya, contohnya adalah Bidang Kependudukan yang menggunakan sistem Kartu Tanda Penduduk Elektronik (e-KTP) yang terintegrasi, lalu di Provinsi DKI Jakarta telah menggunakan e-budgeting(Perencanaan Anggaran dengan sistem informasi). Manfaat dalam penerapan teknologi informasi tersebut adalah efisiensi dan mengurangi biaya operasional dan juga dapat menerapkan pelayanan yang baik kepada pengguna.

Sejak Tahun 2015 yang lalu, Pemerintah Indonesia sedang mengejar target penerimaan pajak masyarakat yang seharusnya memenuhi kewajibannya. Segala bentuk kemudahan ditawarkan Pemerintah agar dapat menarik Wajib Pajak (WP) untuk melaksanakan kewajibannya sebagai Warga Negara Indonesia (WNI). Kemudahan tersebut mulai dari kerjasama antara bank-bank swasta di Indonesia agar dapat menerima pembayaran pajak yang dulunya hanya kantor pos saja sebagai satu-satunya channel yang dapat menerima pembayaran pajak, lalu sistem pembayaran pajak dengan sistem online yang dikeluarkan oleh Direktorat Jenderal Pajak (DJP), yaitu dengan menggunakan Surat Setoran Elektronik (SSE) sehingga tidak perlu lagi melakukan pengisian Surat Setoran Pajak (SSP) secara manual. SSE ini dapat diisi / dibuat di website sse.pajak.go.id yang lebih dikenal sebagai e-billing Pajak versi 1 . Tetapi dalam perkembangannya e-billing pajak versi 1 terdapat kelemahan, seperti tidak terintegrasinya dengan halaman DJP Online, 1 email dapat digunakan berkali-kali untuk membuat akun yang berbeda, lalu tidak adanya kode pengenal khusus bagi WP yang ingin mendaftar.

Melihat masih terdapat kelemahan di e-billing pajak versi 1, Direktorat Jenderal Pajak berinovasi dengan meluncurkan e-billing pajak versi 2 yang dinilai lebih baik dari generasi sebelumnya. Kelebihan $e$-billing pajak versi 2 dapat menjawab segala kelemahan di $e$ billing pajak versi 1 , yaitu sudah terintegrasi dengan DJP Online, 1 email hanya dapat digunakan 1 akun (WP yang bersangkutan), lalu adanya E-FIN atau Electronic Filling Identification Number. E-FIN sendiri adalah kode pengenal unik yang diberikan DJP berbeda-beda setiap WP yang harus diperlukan pada saat membuat akun e-billing pajak versi 2, apabila tidak menggunakan E-FIN maka tidak dapat masuk ke e-billing pajak versi 2.

Faktanya seperti dilansir dari situs liputan6.com realisasi penerimaan pajak 2016 hanya mencapai 85\%, dan itupun dikarenakan adanya prgram Tax Amnesty di tahun 2016. Sebelumnya, pada bulan Oktober hanya $64,2 \%$ realisasinya.Meskipun sudah diberlakukannya sistem e-billing pajak versi 2 tetapi kurang bisa meningkatkan kesadaran pembayaran pajak di Indonesia.

Maka dari itu, penelitian akan berfokus pada faktor-faktor apa saja yang mempengaruhi penerimaan sistem e-billing pajak versi 2 sebagai sarana dalam pemenuhan kewajiban WP orang pribadi.

Penelitian mengenai topik teknologi dan sistem informasi banyak menggunakan Technology Acceptance Model (TAM) yang dicetuskan oleh Davis et. al pada tahun 1989. Model TAM pada dasarnya merupakan penjelasan hubungan antara persepsi kegunaan (Perceived Usefulness) dan persepsi kemudahan (Perceived ease of use) terhadap niat 
untuk menggunakan (behavioral intention to use) sebuah sistem dan penggunaan nyata (actual system use).

\section{TINJAUAN LITERATUR DAN PERUMUSAN HIPOTESIS}

\section{E-Billing}

E-billing adalah Metoda pembayaran pajak secara elektronik menggunakan Kode Billing. Kode Billing sendiri adalah kode identifikasi yang diterbitkan melalui sistem Billing atas suatu jenis pembayaran atau setoran pajak yang akan dilakukan Wajib Pajak. (www.pajak.go.id). E-billing pajak pertama dirilis pada tahun 2007, lalu disempurnakan lagi menjadi e-billing pajak versi 2 di tahun 2015.

Dalam hal penggunaan e-billing pajak versi 2, Wajib Pajak diharuskan membuat permohonan E-FIN (Electronic Filling Identification Number). E-FIN adalah nomor identitas yang diterbitkan oleh Direktorat Jenderal Pajak (DJP) kepada Wajib Pajak yang melakukan transaksi elektronik dengan DJP. Tata cara dalam penggunaan e-billing pajak versi 2 adalah :

1. Mengajukan permohonan aktivasi E-FIN ke Kantor Pelayanan Pajak (KPP) atau ke Kantor Pelayanan Penyuluhan dan Konsultasi Perpajakan (KP2KP).

2. Setelah memperoleh E-FIN, baru dapat mendaftarkan diri pada website DJP Online yaitu http://djponline.pajak.go.id atau website penyedia layanan SPT Elektronik

3. Setelah memiliki akun DJP Online, kita sudah dapat membayar pajak dengan e-billing dan menyampaikan SPT melalui menu e-filling.

\section{Technology Acceptance Model (TAM)}

Technology Acceptance Model (TAM) dipopulerkan oleh Davis pada tahun 1989. TAM menggunakan TRA sebagai dasar teoritikal untuk menspesifikasi hubungan kausal antara dua kunci kepercayaan (believe) yaitu persepsi manfaat (Perceive Usefulness) dan persepsi kemudahan penggunaan (Perceieved Ease of Use). TAM jauh lebih spesifik dibandingkan dengan TRA, karena TAM ditujukan hanya untuk perilaku penggunaan teknologi komputer (Davis et.al., 1986).

Perceived usefulness (Persepsi Kegunaan) dan Perceived ease of use (Persepsi Kemudahan) adalah variabel yang dijelaskan Davis pada tahun 1989. Perceived usefulness atau persepsi kegunaan dapat diartikan sebagai tingkat kepercayaan pengguna (user) bahwa dalam menggunakan sebuah sistem akan memaksimalkan atau meningkatkan kinerja mereka. Kemudian perceived ease of use atau persepsi kemudahan dapat diartikan sebagai tingkat kepercayaan user bahwa dalam penggunaan suatu sistem tertentu tidak memerlukan usaha yang keras dalam proses pembelajarannya dalam artian dapat dengan mudah dipelajari dan diterapkan.

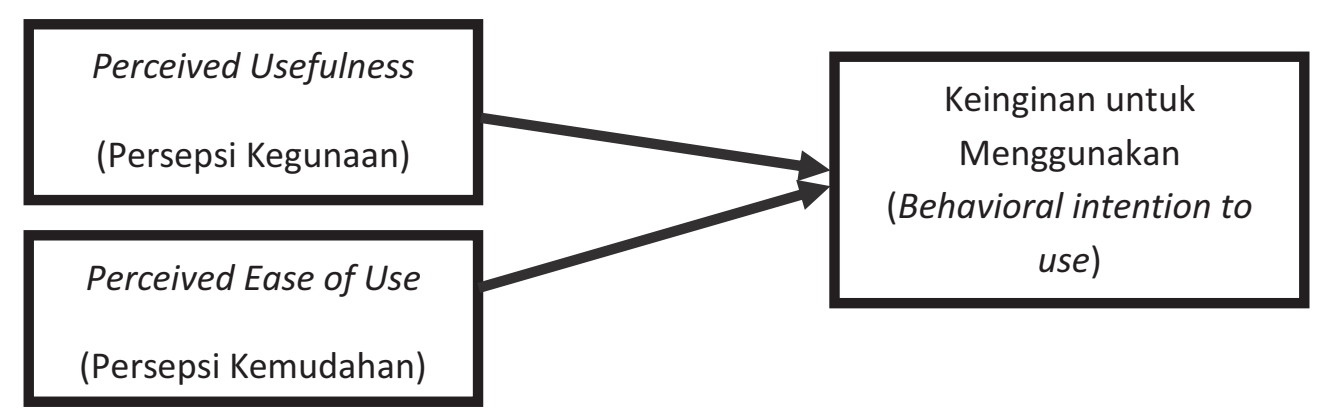

Gambar 1 Model Dasar Pembentukan Persepsi 
Model dasar pembentukan persepsi menurut Davis adalah :

a. Perceived usefulness (PU)

Menyatakan tingkat kepercayaan pengguna bahwa dalam penggunaan teknologi baru akan meningkatkan kinerjanya.

b. Perceived ease of use (PEOU)

Menyatakan tingkat kepercayaan pengguna bahwa dalam mempelajari suatu teknologi baru akan mudah, dan tidak memerlukan usaha yang keras dalam proses pembelajarannya.

c. Behavioral intention to use (BITU) / Keinginan untuk menggunakan

Menyatakan perilaku pengguna ke arah penggunaan teknologi baru tersebut secara berkelanjutan karena dianggap memberikan manfaat.

\section{Perumusan Hipotesis}

Perceived Usefulness atau persepsi kegunaan dapat diartikan sejauh mana seseorang percaya bahwa dalam menggunakan sebuah sistem informasi dapat berguna dalam peningkatan kinerjanya. Menurut penelitian yang dilakukan Davis (1989), persepsi kegunaan terbukti dapat menjelaskan alasan mengapa seseorang menggunakan sistem tersebut. Penelitian yang dilakukan oleh Maria (2015) terbukti bahwa persepsi kegunaan ini berpengaruh signifikan terhadap keinginan Wajib Pajak untuk menggunakan e-filling.

Manfaat dari sebuah sistem tersebut dianggap sebagai faktor yang mempengaruhi minat pengguna untuk menggunakan sistem tersebut. Dalam hal ini semakin tinggi pengguna menganggap bahwa e-billingpajak versi 2 bermanfaat, maka pengguna semakin berkeinginan untuk menggunankannya.Maka dari itu, berdasarkan penjabaran tersebut ditentukan hipotesis sebagai berikut :

\section{H1 : Perceived Usefulness Berpengaruh Terhadap Keinginan Wajib Pajak Orang Pribadi Untuk Menggunakan E-Billing Pajak Versi 2}

Perceived ease of use atau persepsi kemudahan dapat diartikan sejauh mana seseorang percaya bahwa dalam penggunaan sebuah sistem informasi tidak diperlukan usaha yang berat. Dari penelitian Davis (1989) terbukti bahwa faktor ini dapat menjelaskan alasan seseorang dalam menggunakan sebuah sistem informasi.

Semakin pengguna merasa sebuah sistem mudah digunakan, maka dianggap semakin tinggi pula keinginan untuk menggunakan sistem tersebut. Maka dari itu, ditentukan hipotesis sebagai berikut:

\section{H2 : Perceived Ease Of Use Berpengaruh Terhadap Keinginan Wajib Pajak Orang Pribadi Untuk Menggunakan E-Billing Pajak Versi 2}

\section{METODA PENELITIAN}

\section{Populasi, Sampel, Dan Teknik Pengumpulan Sampel}

Populasi adalah kumpulan dari keseluruhan elemen di mana kita akan menarik beberapa kesimpulan (Cooper dan Schindler, 2006). Sedangkan Menurut Kuncoro (2003) Populasi adalah kelompok elemen yang lengkap, yang biasanya berupa orang, objek, transaksi, atau kejadian di mana kita tertarik untuk mempelajarinya atau menjadi objek penelitian. Dapat disimpulkan bahwa populasi dapat disebut benar-benar populasi apabila keseluruhan objek, orang ataupun elemen yang menarik untuk diteliti dan akan ditarik kesimpulan berdasarkan penelitian tersebut. 
Sampel, menurut Kuncoro (2003) adalah suatu himpunan bagian (subset) dari unit populasi. Sampel merupakan bagian dari populasi keseluruhan yang diyakini dapat mewakili keseluruhan populasi. Metoda yang digunakan untuk menentukan sampel pada penelitian ini adalah convenience sampling, yaitu prosedur untuk mendapatkan unit sampel menurut keinginan peneliti (Kuncoro, 2003). Kelebihan dari metoda ini adalah efisiensi waktu dan hemat. Sampel dalam penelitian ini adalah 400 Wajib Pajak Orang Pribadi yang terdaftar di Kantor Pelayanan Pajak Pratama Kota Cirebon hingga tahun 2016. Lokasi penelitian adalah di sekitar Kantor Pelayanan Pajak Pratama Kota Cirebon.

\section{JENIS DAN SUMBER DATA PENELITIAN}

Jenis data pada penelitian ini adalah data primer. Data Primer adalah data yang dikumpulkan dari sumber-sumber asli untuk tujuan tertentu (Kuncoro, 2003). Data primer yang dimaksud dalam penelitian ini adalah persepsi responden yang berasal dari penyebaran kuesioner yang telah dilakukan.

\section{DEFINISI DAN PENGUKURAN VARIABEL}

\section{Perceived Usefulness (PU)}

Perceived usefulness atau persepsi kegunaan dalam penelitian ini yaitu pemahaman Wajib Pajak Orang Pribadi (WP OP) bahwa dalam penggunaan e-billing pajak versi 2 dapat meningkatkan kinerja dan bermanfaat baginya. Persepsi kebermanfaatan yang digunakan dalam penelitian ini mengadopsi dari Davis, F.D. (1989), beberapa indikatornya yaitu:

a) Memudahkan aktifitas (PU 1)

b) Mengurangi tingkat kesalahan/error (PU 2)

c) Menghemat waktu dan energi (PU 3)

d) Meningkatkan produktivitas (PU 4)

Indikator tersebut diukur dengan menggunakan tipe skala perilaku (attitude scales) yaitu suatu kumpulan alat pengukuran yang mengukur tanggapan individu terhadap suatu objek atau fenomena (Kuncoro, 2003), dan yang akan digunakan adalah skala likert (likert scale), yaitu di mana responden menyatakan tingkat setuju atau tidak setuju mengenai berbagai pernyataan mengenai perilaku, objek, orang, atau kejadian. (Kuncoro, 2003). Skala Likert ini dipakai untuk mengukur respon subyek kedalam 4 poin dengan interval yang sama yaitu:

1. 1 = sangat tidak setuju (STS)

2. 2 = tidak setuju (TS)

3. 3 = setuju (S)

4. 4 = sangat setuju (SS)

Interpretasi hasil tersebut menunjukan semakin besar kesesuaian pernyataan terhadap persepsi responden, maka skor akan semakin besar dan semakin besar skor ini dapat diartikan semakin tinggi nya persepsi kegunaan responden terhadap e-billing pajak versi 2 .Sedangkan semakin kecil pernyataan terhadapa persepsi responden, maka skor akan semakin kecil dan semakin kecilnya skor ini dapat diartikan bahwa persepsi kegunaan responden terhadap e-billing pajak versi 2 rendah.

2. Perceived Ease Of Use (PEOU)

Perceived ease of use atau persepsi kemudahan didalam penelitian ini adalah tingkat keyakinan responden terhadap e-billing pajak versi 2 mudah dipahami dan 
digunakan.Persepsi kemudahan yang akan digunakan dalam penelitian ini mengadopsi model Davis, F.D. (1989). Beberapa indikatornya adalah:

1. Mudah dipahami atau dipelajari (PEOU 1)

2. Mudah dioperasikan (PEOU 2)

3. Mudah untuk menjadi mahir (PEOU 3)

Indikator tersebut diukur dengan menggunakan tipe skala interval dengan memakai metoda perskalaan rating yaitu Skala Likert. Skala Likert ini dipakai untuk mengukur respon subyek kedalam 4 poin dengan interval yang sama yaitu:

1. 1 = sangat tidak setuju (STS)

2. 2 = tidak setuju (TS)

3. 3 = setuju $(\mathrm{S})$

4. 4 = sangat setuju (SS)

Interpretasi hasil tersebut menunjukan semakin besar kesesuaian pernyataan terhadap persepsi responden maka skor akan semakin besar dan semakin besar skor ini dapat diartikan bahwa persepsi kemudahan WP OP terhadap e-billing pajak versi 2 juga semakin tinggi. Sedangkan semakin kecil kesesuaian pernyataan terhadap persepsi responden maka skor akan semakin kecil dan semakin kecilnya skor ini dapat diartikan bahwa persepsi kemudahan responden terhadap e-billing pajak versi 2 pun rendah.

\section{Behavioral intention to use (BITU)}

Behavioral intention to use atau keinginan untuk menggunakan dapat didefiniskan sebagai kecenderungan Wajib Pajak Orang Pribadi untuk menggunakan e-billing pajak versi 2 di kemudian hari. Hal ini didukung dengan kecenderungan pengguna untuk tetap menggunakan e-billing pajak versi 2 , serta merekomendasikan kepada pengguna lain yang belum menggunakan e-billing pajak versi 2 . Beberapa indikatornya adalah :

1. Merekomendasikan kepada orang lain (BITU1)

2. Pengguna menggunakan sendiri teknologi tersebut (BITU2), dan

3. Tetap menggunakan walau ada pilihan lain (BITU3)

Indikator tersebut diukur dengan menggunakan tipe skala interval yaitu dengan menggunakan Skala Likert. Skala Likert ini digunakan dengan mengukur respon subyek ke dalam 4 poin skala dengan interval yang sama yaitu :

1. 1 = Sangat Tidak Setuju (STS)

2. 2 = Tidak Setuju (TS)

3. 3 = Setuju (S)

4. 4 = Sangat Setuju (SS)

Interpretasi hasil tersebut menunjukan semakin besar kesesuaian pernyataan terhadap persepsi responden maka skor akan semakin besar dan semakin besar skor ini dapat diartikan bahwa keinginan responden untuk menggunakan e-billing pajak versi 2 juga semakin tinggi. Sedangkan semakin kecil kesesuaian pernyataan terhadap persepsi responden maka skor akan semakin kecil dan semakin kecilnya skor ini dapat diartikan bahwa keinginan responden untuk menggunakan e-billing pajak versi 2 pun rendah.

\section{HASIL DAN PEMBAHASAN}

\section{Statistik Deskriptif}

Jumlah kuesioner yang disebar sebanyak 500 buah, kuesioner yang kembali sebanyak 462 buah, dengan kuesioner tidak sah sebanyak 27 buah dikarenakan bukan Wajib Pajak Orang Pribadi (WP OP) yang terdaftar di Kota Cirebon. Sehingga kuesioner yang dapat diolah hanya 435 buah. Jumlah responden dalam penelitian ini sebanyak 435 orang yang 
terdiri dari 247 orang berjenis kelamin laki-laki, dan 188 orang berjenis kelamin perempuan.

Dalam penelitian ini rata-rata usia responden adalah 36,06 dengan usia tertinggi adalah 61 sedangkan yang terendah berusia 20 . Responden paling banyak berada pada usia 29 tahun, yaitu 29 orang. Dalam Penelitian ini, sebanyak 91\% responden melakukan pembayaran pajaknya sendiri, dan hanya $9 \%$ yang tidak membayar pajak sendiri atau dibayarkan oleh pihak lain. Sebanyak $90 \%$ responden mengetahui tentang e-billing pajak versi 2 , dan hanya sebanyak $10 \%$ responden saja yang benar-benar tidak mengetahui $e$ billing pajak versi 2 . Sebanyak $87 \%$ responden menggunakan e-billingpajak versi 2 dalam proses pembayaran pajak mereka, dan hanya $13 \%$ saja yang tidak/belum menggunakan $e$ billingpajak versi 2.Dari hasil pengumpulan kuesioner sebanyak $13 \%$ responden ada yang masih menggunakan SSP manual dan juga e-billing versi 1.

\section{Uji Asumsi Klasik}

Uji Normalitas

Pengujian normalitas bertujuan untuk mengetahui apakah data yang akan diuji merupakan data empiris yang memenuhi hakikat naturalistik. Hakikat ini menganut faham yaitu gejala yang terjadi berlangsung secara wajar dengan kencederungan memiliki pola yang teratur. Pengujian normalitas ini menggunakan analisis statistik yaitu dengan kolmogorov smirnov atas standardized residual. (Murniati et al., 2013)

Tabel 1

Hasil Uji Normalitas

One-Sample Kolmogorov-Smirnov Test

\begin{tabular}{|ll|r|}
\hline N & \multicolumn{1}{c|}{$\begin{array}{c}\text { Standardized } \\
\text { Residual }\end{array}$} \\
\hline Normal Parameters ${ }^{a, b} \quad$ Mean & 435 \\
Most Extreme Differences & Std. Deviation &, 0000000 \\
& Positive &, 99306350 \\
Kolmogorov-Smirnov $Z$ &, 131 \\
Asymp. Sig. (2-tailed) & &, 131 \\
\end{tabular}

Tabel 1 menampilkan hasil uji normalitas. Dari hasil perhitungan diatas, didapatkan nilai kolmogorov smirnov sebesar 2,727 yaitu lebih besar dari taraf signifikansi sebesar 0,01 , yang dapat diartikan bahwa data terdistribusi secara normal.

\section{Uji Heteroskedastisitas}

Didalam analisi regresi, kondisi heteroskedastisitas adalah dimana variasi variabel independen berbeda-beda terhadap data yang dimiliki. Seharusnya, kesalahan / error memiliki variasi yang seragam pada tiap-tiap sampelnya (homokedastisitas). Pengujian asumsi ini dapat dilakukan dengan uji glejser. Uji Glejser dilakukan dengan meregresi variabel independen terhadap nilai absolut residual (Gujarati, 2012 dalam Murniati et al., 2013). 


\section{Hasil Uji Heteroskedastisitas}

\begin{tabular}{|c|c|c|c|c|c|c|}
\hline \multicolumn{7}{|c|}{ Coefficients $^{\Xi}$} \\
\hline \multirow{2}{*}{\multicolumn{2}{|c|}{ Model }} & \multicolumn{2}{|c|}{ Unstandardized Coefficients } & \multirow{2}{*}{$\begin{array}{c}\begin{array}{c}\text { Standardized } \\
\text { Coefficients }\end{array} \\
\text { Beta }\end{array}$} & \multirow[b]{2}{*}{$t$} & \multirow[b]{2}{*}{ Sig. } \\
\hline & & $B$ & Std. Error & & & \\
\hline \multirow[t]{3}{*}{1} & (Constant) &,- 128 & .292 & &,- 439 & .661 \\
\hline & $\mathrm{PU}$ & .051 & .029 & .108 & 1,791 & .074 \\
\hline & PEOU &, 073 &, 044 &, 100 & 1,664 &, 097 \\
\hline
\end{tabular}

Tabel 2 menampilkan hasil uji heteroskedastisitas. Dari hasil perhitungan, didapatkan hasil sig untuk variabel perceived usefulness sebesar 0,074 yaitu lebih besar dari 0,01 yang artinya tidak terdapat heteroskedastisitas untuk variabel perceived usefulness. Sedangkan untuk variabel perceived ease of use nilai sig sebesar 0,097 yaitu lebih besar dari 0,01 yang artinya tidak terdapat hetersokedastisitas pula untuk variabel perceived ease of use.

\section{Uji Multikolinearitas}

Multikolinearitas adalah sebuah situasi yang menunjukkan adanya korelasi atau hubungan kuat antara dua variabel bebas atau lebih dalam sebuah model regresi berganda

Tabel 3

\section{Hasil Uji Multikolinearitas}

\begin{tabular}{|c|c|c|c|c|c|c|c|c|}
\hline \multicolumn{9}{|c|}{ Coefficients $^{\Xi}$} \\
\hline \multirow{2}{*}{\multicolumn{2}{|c|}{ Model }} & \multicolumn{2}{|c|}{ Unstandardized Coefficients } & \multirow{2}{*}{$\begin{array}{c}\begin{array}{c}\text { Standardized } \\
\text { Coefficients }\end{array} \\
\text { Beta }\end{array}$} & \multirow[b]{2}{*}{$t$} & \multirow[b]{2}{*}{ Sig. } & \multicolumn{2}{|c|}{ Collinearity Statistics } \\
\hline & & $\mathrm{B}$ & Std. Error & & & & Tolerance & VIF \\
\hline \multirow[t]{3}{*}{1} & (Constant) & 2,910 & .461 & & 6,316 &, 000 & & \\
\hline & PU & .232 &, 045 &, 256 & 5,123 &, 000 & 619 & 1,616 \\
\hline & PEOU & .525 &, 069 &, 380 & 7,591 &, 000 & .619 & 1,616 \\
\hline
\end{tabular}

Tabel 3 menyajikan hasil pengujian multikolinearitas. Dari hasil perhitungan tersebut didapatkan hasil VIF di sekitar angka 1 dan tidak lebih dari 10 serta nilai tolerance mendekati 1, sehingga dapat dikatakn bahwa dalam model regresi ini tidak terdapat masalah multikolinearitas.

\section{Analisis Regresi}

R-Square merupakan koefisien determinasi yang umum digunakan untuk mengevaluasi model fit. R-square adalah 1 dikurangi rasio variabilitas residual. Ketika variabilitas dari nilai sisa sekitar garis regresi relatif terhadap variabilitas keseluruhan kecil, prediksi dari persamaan regresi baik. (Murniati et al., 2013)

Dari hasil output SPSS tersebut dapat dilihat nilai $\mathrm{R}$ Square $\left(\mathrm{R}^{2}\right)$ sebesar 0,33 atau $33 \%$ yang artinya bahwa variabel perceived usefulness dan perceived ease of use mampu menjelaskan sebanyak 33\% variasi behavioral intention to use. Sedangkan sebanyak $42,5 \%$ dijelaskan oleh variabel lain diluar model regresi.

Model Summary

\begin{tabular}{|l|l|r|r|r|}
\hline Model & $\mathrm{R}$ & R Square & \multicolumn{1}{|c|}{$\begin{array}{c}\text { Adjusted R } \\
\text { Square }\end{array}$} & $\begin{array}{c}\text { Std. Error of } \\
\text { the Estimate }\end{array}$ \\
\hline 1 & $.575^{\mathrm{a}}$ &, 330 &, 327 & 1,280 \\
\hline
\end{tabular}

Gambar 1 Hasil Penguiian Koefisien Determinasi (R Square) 


\section{Uji t (Signifikansi Individual)}

Uji t atau uji signifikansi parameter individual menunjukkan seberapa besar pengaruh variabel independen secara individual terhadap variabel dependen (Murniati dkk, 2013). Indikator penerimaan hipotesisnya adalah sebagai berikut :

1. Jika sig $<0,01$; maka variabel independen berpengaruh terhadap variabel dependen

2. Sebaliknya apabila sig $>0,01$ maka variabel independen tidak berpengaruh terhadap variabel dependen.

Tabel 4

\section{Hasil Analisis Regresi}

Coefficients ${ }^{\mathrm{a}}$

\begin{tabular}{|ll|r|r|r|r|r|}
\hline \multirow{2}{*}{ Model } & \multicolumn{2}{|c|}{ Unstandardized Coefficients } & \multicolumn{2}{c|}{$\begin{array}{c}\text { Standardized } \\
\text { Coefficients }\end{array}$} & \\
\cline { 3 - 5 } & \multicolumn{1}{|c|}{$\mathrm{B}$} & \multicolumn{1}{c|}{ Std. Error } & \multicolumn{1}{c|}{ Beta } & \multicolumn{1}{c|}{ Sig. } \\
\hline 1 & (Constant) & 2,910 &, 461 & & 6,316 &, 000 \\
& PU &, 232 &, 045 &, 256 & 5,123 &, 000 \\
& PEOU &, 525 &, 069 &, 380 & 7,591 &, 000 \\
\hline
\end{tabular}

Dari hasil perhitungan SPSS, didapatkan hasil sig sebesar 0,00 baik untuk variabel perceived usefulness dan variabel perceived ease of use. Pada $\alpha$ sebesar $1 \%$ dengan melihat indikator penerimaan hipotesis maka, variabel perceived usefulness dan perceived ease of use dapat dikatakan berpengaruh positif terhadap behavioral intention to use (keinginan untuk menggunakan). Sehingga dapat dinyatakan sebagai berikut :

Tabel 5 Penerimaan Hipotesis

\begin{tabular}{|l|c|}
\hline \multicolumn{1}{|c|}{ Hipotesis } & Indikator Penerimaan \\
\hline $\begin{array}{l}\text { H1 : Perceived Usefulness berpengaruh terhadap keinginan Wajib Pajak } \\
\text { Orang Pribadi untuk menggunakan e-billing pajak versi } 2\end{array}$ & DITERIMA \\
\hline $\begin{array}{l}\text { H2 : Perceived Ease of Use berpengaruh terhadap keinginan Wajib } \\
\text { Pajak Orang Pribadi untuk menggunakan e-billing pajak versi } 2\end{array}$ & DITERIMA \\
\hline
\end{tabular}

\section{SIMPULAN}

Berdasarkan hasil perhitungan dan analisis data yang telah dilakukan, dapat ditarik beberapa kesimpulan sebagai berikut :

1. Perceived usefulness secara signifikan mempengaruhi keinginan Wajib Pajak Orang Pribadi Kota Cirebon untuk menggunakan e-billing pajak versi 2, yang artinya penting untuk dilakukannya sosialisasi tentang berbagai macam manfaat dan keunggulan yang dimiliki e-billing pajak versi 2 dibanding dengan generasi sebelumnya maupun Surat Setoran Pajak manual.

2. Perceived ease of use secara signifikan pula mempengaruhi keinginan Wajib Pajak Orang Pribadi Kota Cirebon untuk menggunakan e-billing pajak versi 2, dengan artian selain memahami apa saja keunggulan dan manfaat dari e-billing pajak versi 2, mereka juga membutuhkan pengetahuan tentang cara pengoperasian sistem tersebut sehingga terdorong untuk menggunakannya. 
3. Dari sebanyak 435 sampel yang berhasil dikumpulkan, sebanyak $90 \%$ diantaranya mengetahui e-billing pajak versi 2 tetapi $87 \%$ saja yang benar-benar sudah menggunakannya. Sebanyak $13 \%$ dari responden masih memilih untuk menggunakan SSP manual dan e-billing pajak versi 1.

\section{SARAN}

Dari hasil proses pengambilan kuesioner, penulis menyarankan Pemerintah Pusat maupun Daerah dirasa perlu untuk mendukung modernisasi dalam tata cara pembayaran pajak dalam hal pelatihan penggunaan komputer dan internet secara mendasar kepada masyarakat yang belum memahaminya.Disamping sosialisasi yang telah dilakukan oleh Pemerintah, hal ini menjadi perhatian karena berdasarkan pengalaman di lapangan, para Wajib Pajak rela datang ke Kantor Pelayanan Pajak (KPP) hanya untuk membuat kode billing untuk membayarkan pajak dikarenakan tidak mengerti cara menggunakan komputer atau internet di rumah. Tentu saja proses ini memakan waktu lama karena jumlah perangkat di KPP sehingga harus mengantre.

\section{Untuk Kantor Pelayanan Pajak}

Pihak Kantor Pelayanan Pajak dirasa perlu untuk lebih mensosialisasikan keunggulan serta manfaat dan tata cara pembayaran pajak dengan menggunakan e-billing pajak versi 2. Hal yang dapat dilakukan seperti pembuatan X-banner tentang alur proses penggunaan e-billing mulai dari pengajuan E-FIN sampai WP dapat menggunakan sendiri dimanapun tanpa harus mengantre di KPP, undangan untuk pelatihan penggunaan sistem perpajakan yang terbuka secara umum, dan bisa juga dengan membuka stand-stand di pameran dengan membagikan brosur. Dalam segi penggunaannya, KPP dirasa perlu untuk secara berkala mengadakan sosialisasi tentang penggunaan e-billing secara praktek.

\section{Untuk Masyarakat Secara Umum}

Diharapkan masyarakat sceara umum agar lebih ditumbuhkan rasa ingin tahu dengan perkembangan teknologi baik dari segi pembayaran pajak dan sistem lainnya. Masyarakat diharapkan tidak takut dahulu sebelum mencoba sistem yang baru, pasti di setiap pembaharuan sistem terdapat kelebihan dengan konsekuensi belajar hal baru lagi.

\section{Keterbatasan Penelitian}

Dalam penelitian ini ada beberapa keterbatasan yang dirasa dapat disempurnakan lagi pada penelitian berikutnya, yaitu sebagai berikut :

1. Masih terdapat $42,5 \%$ variabel di luar model regresi yang dapat menjelaskan keinginan seseorang dalam menggunakan e-billing pajak versi 2. Diharapkan dapat menambah atau mengganti variabel untuk penelitian berikutnya.

2. Dalam penelitian ini sebenarnya ingin memasukkan variabel gender dan usia sebagai faktor yang memperngaruhi penerimaan terhadap sebuah sistem, tetapi data dari KPP tidak dapat menampilkan jumlah WP OP berdasarkan gender dan usia (hanya berupa jumlah WP OP aktif secara keseluruhan). 


\section{DAFTAR PUSTAKA}

Cooper, D dan P. S. Schindler. Alih Bahasa oleh Budijanto., dan Djunaedi. 2006. Metoda Riset BisnisVol 2. Jakarta : PT Media Global Edukasi.

Davis, F.D et. al .1989. Perceived Usefulness, Perceived Ease of Use, And User Acceptance of Information Technology.MIS Quarterly Vol. 13 No 3 : 319-340

Direktorat Jenderal Pajak.2015.e-Billing. Direktorat Jenderal Pajak. Diakses pada 22 Februari 2017, dari http://www.pajak.go.id/e-billing

Ghozali, I. 2001. Aplikasi analisis Multivariate dengan Program SPSS. Semarang: Badan Penerbit Universitas Diponegoro

Hartono, J. 2011.Metoda Penelitian Bisnis:Salah Kaprah dan Pengalaman-Pengalaman. Edisi 6. Yogyakarta:BPFE UGM.

Imaculata, A. 2015. Analisis faktor- Faktor yang Mempengaruhi Penerimaan Wajib Pajak Orang Pribadi Terhadap E-Filing. Skripsi Strata 1 Universitas Katolik Soegijapranata Semarang.

Kuncoro, M. 2003. Metoda Riset untuk Bisnis dan Ekonomi. Jakarta : Erlangga

Ariyanti, F. 2016. Tax Amnesty Berhasil, Ini Prediksi Penerimaan Pajak di 2016. Diakses pada 14 Desember 2016, dari http://bisnis.liputan6.com/read/2659624/tax-amnestyberhasil-ini-prediksi-penerimaan-pajak-di-2016

Prasetyo, N. S. L. 2013. Analisis Perceived Usefulness, Perceived Ease of Use, dan Perceived Enjoyment Terhadap Sikap Mahasiswa pada Sistem Pembayaran Melalui Virtual Account di Unika Soegijapranata Semarang. Skripsi Strata 1 Universitas Katolik Soegijapranata Semarang.

Hidayat, A. 2013. Tutorial Linearitas Regresi dengan SPSS. Diakses pada 6 April 2017, dari https://www.statistikian.com/2013/03/linearitas-regresi.html

Kho, D. 2016. Analisis Regresi Linear Sederhana (Simple Linear Regression).Diakses pada 12 Maret 2017, dari http://teknikelektronika.com/analisis-regresi-linear-sederhanasimple-linear-regression/ 